IX International Scientific Symposium

"Farm Machinery and Processes Management in Sustainable Agriculture", Lublin, Poland, 2017

DOI: $10.24326 /$ fmpmsa.2017.21

\title{
EVALUATION OF STREIF'S INDEX VALUES DURING MATURATION OF TWO APPLE CULTIVARS
}

\section{Tomasz GUZ, Zbigniew KOBUS, Rafal NADULSKI, Leszek RYDZAK}

Department of Food Engineering and Machinery, University of Life Sciences in Lublin, POLAND

E-mail of corresponding author: tomek.guz@up.lublin.pl

Keywords: apples, harvest, product optimization, Streif's index

\begin{abstract}
The paper presents the results of Streif's Index (SI) expression by new method of harvest date optimization, based on calculation one of its components - starch index (S), by image analysis. Harvest date prediction is a crucial factor in apple storage and subsequent shelf life, making it the main factor of product optimization. Apple fruits (Gloster and Rubin) after harvest were subjected to measurements of firmness, extract, and calculation of starch degradation as the main indicators of fruit storage suitability. The work presents basic changes of maturity indicators to assess credibility of its value in various stages of ripening. The results present that the use of precise digital image analysis reduces inaccuracies of Streif's Index to more test limits set. Streif's index value in the range of $0,7-0,8$ for Rubin apples and $3-4$ for Gloster, at which harvest of fruits is recommended, was obtained at different harvest dates for image analysis results based on different image filtration thresholds. This type of image analysis inaccuracies emerged as the main factor of SI deviations.
\end{abstract}

\section{INTRODUCTION}

New methods of storage and fruit processing require outside storage compartments with suitable equipment to ensure the maintenance of proper composition of the atmosphere, temperature and humidity and even pressure (Malinowska-Pańczyk, Kołodziejska 2010), the commodity collected at the optimum time, which determines its suitability for storage under the given conditions (Rutkowski 2001). Depending on their purpose, the harvest of fruit can be indicated that many methods (De Long 1999). If the fruits are intended for long term storage, the harvest period is determined on the basis of their physiological state (McGlasson et al. 2005). The state of physiological suitability is specified by fruit flesh firmness (Billy 2008), the ethylene content in the seed slot (Song, Bangerth 1996), soluble solids content and starch content (Łysiak 1998). The last indicator - starch index is performed in a simple, reliable test, possible to execute without sophisticated laboratory equipment (Jackman, Sun 2013). The starch content in apples, changes during maturation (Amissah et al. 2006). The initialization of its degradation is observed in August, and in September it undergoes a sudden acceleration (Doerflinger et al. 2015). As a result of starch degradation a set of monosaccharides appear in the fruit, which presence increases the concentration of soluble solids in the fruit juice (Fellman et al. 2003). Biochemical processes in the fruit during its maturation cause softening of the flesh, resulting in a gradual decrease in the firmness (Billy et al. 2008, Morales et al. 2007), The measurement of these three indicators is necessary to determine the aggregate index, the value of which is the basis for the decision to set. The most popular harvest indicator is the Streif's index. The results of fruit firmness and soluble solids content usually doesn't cause problems when it comes to readings taken from the instrument affected by constant, and small inaccuracy, usually given by its producer (Lysiak 1998,). Estimation of starch index with sufficient precision is, however, hard to perform, because it is based on visual, subjective assessment. The divergence in the assessment test in the group making the determination using standard tables reaches up to 60\% (Peirs et al. 2002). The accuracy in estimation of this index plays important role on decision that directly determines the quality of fruit. 
This paper proposes a calculation of starch index by digital images analysis, recorded during maturation of fruit.

\section{MATERIALS AND METHODS}

Apples (cv. Gloster and Rubin) were harvested in 4-days intervals. After the harvest, 10 apples picked from the trees were cut at equilibrium and subjected to standard starch test. Halves coloured by solution were cut to $5 \mathrm{~mm}$ thick slices. Those specimens were placed on illuminator screen and photographed by CCD 8-bit image converter camera. After photographs had been taken, picture analysis was conducted due to estimate the starch index values. The principle of measurement is illustrated by fig. 1 .

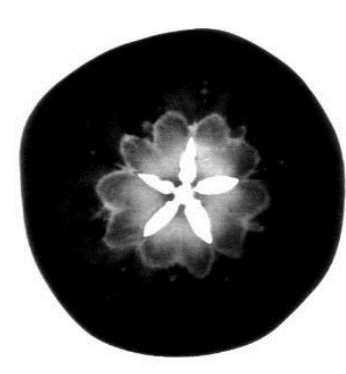

A

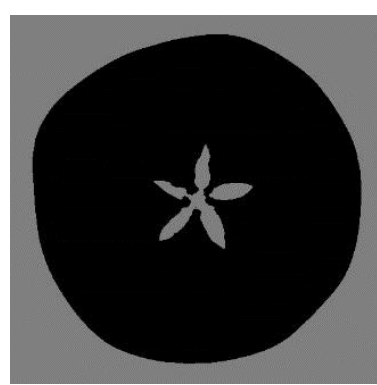

$\mathrm{B}$

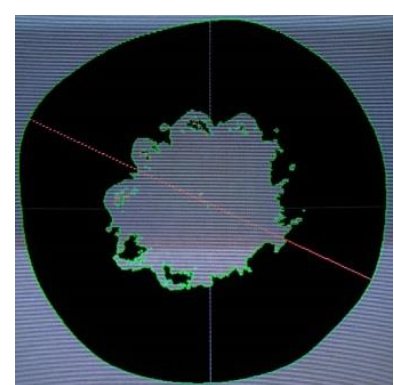

C

Fig. 1. Stages of image transformation: A - slice image with starch pattern (primary image),

$\mathrm{B}$ - binary image of the whole slice area, $\mathrm{C}$ - binary image of starch occupied area during measurement procedure

The starch index value was computed by the use of the formula:

$$
S=10\left(1-\frac{p_{w}}{p_{c}}\right),
$$

where:

$\mathrm{S}$ - starch index value,

$\mathrm{p}_{\mathrm{c}}-$ the whole slice area,

$\mathrm{p}_{\mathrm{w}}-$ the area occupied by starch pattern.

The second halve of apples were used to extract measurements. The apple flesh was mashed and juice was filtered by the piece of blotter due to extract measurements (Atago refractometer, $\pm 0,1 \mathrm{Brix}$ ). The next 10 fruits in the sample batch were used to texture measurements. Firmness of the fruits was measured by the use of $11 \mathrm{~mm}$ penetrometer, which was immerged to $8 \mathrm{~mm}$ into apple flesh with the constant speed of $0,83 \mathrm{~mm} / \mathrm{s}$. The resistance force (firmness) $\mathrm{F}$ was measured during the test, performed by TA.XT Plus texturometer. After all measurements were accomplished, the Streif's index was calculated:

$$
I S=\frac{F}{R * S},
$$

where:

F- firmness of apple flesh $[\mathrm{N}]$,

$\mathrm{R}$ - soluble solids by refractometer [Brix],

$\mathrm{S}$ - starch index value. 


\section{RESULTS}

The values of starch index estimated in the experiment were shown in table 1 and 2 . The line of its changes indicates very different starch decomposition, described by computer image analysis. Optimum values of Streif's index (SI) at harvest are given in bold and underlined (Tab. $1-2)$. Relative deviations calculated in most harvest dates are above $10 \%$ (calculated as deviations from mean values). The errors calculated for terminal dates of harvest are smaller and their values are about $2-3 \%$. Results obtained from image filtration threshold of 120 in 8-bit depth of colour, was the base of all calculations. The filtration threshold of $s=120$ was the base of all calculations. The deviated values of SI were calculated $b$ the use of different threshold filters: $s$ 100, s110, s115, s125, s130, s140 which were chosen by the analysis of area occupied by starch in the primary pictures.

The values of starch index as a main factor of Streif's harvest index were estimated by computer image analysis. All the data are collected in the table 1.

Gloster fruits are an example of apples where starch deterioration represents circulartype pattern on the cross section of fruit halves. These fruits should be harvested when Streif's index is in the range of $3-4$. This maturity phase was observed in at most two harvest dates for each filtration procedure. Table 1 presents SI changes at different starch index $(\mathrm{S})$ values, caused by variable filtration thresholds.

Tab. 1. Changes of Streif's index values in Gloster apples caused by variable image filtration threshold

\begin{tabular}{|c|c|c|c|c|c|c|c|}
\hline $\begin{array}{c}\text { Harvest } \\
\text { date } \\
\text { (Day of } \\
\text { the year) }\end{array}$ & SI 100 & SI 110 & SI 115 & SI 120 & SI 125 & SI 130 & SI 140 \\
\hline 253 & $\underline{\mathbf{3 , 0 6}}$ & 4,45 & 5,89 & 9,37 & 11,14 & 14,39 & 21,60 \\
\hline 257 & 2,57 & $\underline{\mathbf{3 , 4 0}}$ & 4,44 & 5,70 & 8,54 & 10,87 & 15,70 \\
\hline 261 & 2,06 & 2,55 & $\underline{\mathbf{3 , 3 2}}$ & 4,32 & 5,38 & 7,08 & 9,87 \\
\hline 265 & 1,70 & 2,11 & 2,74 & $\underline{\mathbf{3 , 3 3}}$ & $\underline{\mathbf{4 , 0 0}}$ & 5,19 & 7,18 \\
\hline 269 & 1,46 & 1,78 & 2,35 & 2,68 & $\underline{\mathbf{3 , 1 9}}$ & $\underline{\mathbf{4 , 1 4}}$ & 5,20 \\
\hline 273 & 1,34 & 1,69 & 2,04 & 2,32 & 2,68 & $\underline{\mathbf{3 , 3 1}}$ & $\underline{\mathbf{3 , 9 9}}$ \\
\hline 277 & 1,22 & 1,48 & 1,89 & 2,19 & 2,42 & 2,82 & $\underline{\mathbf{3 , 4 9}}$ \\
\hline 281 & 1,06 & 1,27 & 1,63 & 1,85 & 2,10 & 2,35 & 2,87 \\
\hline 285 & 0,98 & 1,13 & 1,41 & 1,60 & 1,74 & 1,96 & 2,32 \\
\hline 289 & 0,84 & 0,95 & 1,10 & 1,27 & 1,43 & 1,55 & 1,86 \\
\hline 293 & 0,75 & 0,80 & 0,88 & 1,00 & 1,12 & 1,26 & 1,48 \\
\hline 297 & 0,66 & 0,69 & 0,73 & 0,80 & 0,91 & 1,03 & 1,25 \\
\hline
\end{tabular}

Filtration thresholds at the range of $100-140$ resulted in huge dispersion of possible harvest dates ( 253 to 281 day of the year). The initial harvest dates are taking into account harvest dates in many years before the experiment was performed. According to SI values obtained in the experiment, the optimum filtration value for primary images should be set above threshold of 120 (t120). The most appropriate value, observed on the basis of results obtained in the experiment, was t130. SI results obtained on the basis of image filtration t130 were probably the most suitable for optimum harvest date, placing it between 273 and 277 day of the year, which is the most possible "harvest window" period for apples intended for long-term storage.

Rubin apples are an example of fruits where cross-section starch decline during its maturation represents radial-type $S$ deterioration, which is expressed by irregular starch pattern of areas where starch vanished. Harvest date is suggested when Streif's index is 
in the range of $0,7-0,8$. Following this recommendation, SI optimum values were obtained relatively late. The basis filtration threshold (t120) and upper values resulted in very late harvest dates (Tab. 2). This means that filtration procedure based on this threshold values leads to false results in starch index evaluations. Assuming this, the lower values of filtration thresholds (under t120) are recommended. The explanation of these results leads to conclusion, that increasing of threshold values resulted in expanding area occupied by starch-iodine complex, thus the $S$ values were calculated as false, based on abnormal large areas, created as the result of improperly applied threshold values.

Tab. 2. Changes of Streif's index values in Rubin apples caused by variable image filtration threshold

\begin{tabular}{|c|c|c|c|c|c|c|c|}
\hline $\begin{array}{c}\text { Harvest } \\
\text { date } \\
\text { (Day of } \\
\text { the year) }\end{array}$ & SI 100 & SI 110 & SI 115 & SI 120 & SI 125 & SI 130 & SI 140 \\
\hline 253 & 1,55 & 1,75 & 1,99 & 2,12 & 2,34 & 2,54 & 2,94 \\
\hline 257 & 1,41 & 1,57 & 1,74 & 1,90 & 2,04 & 2,20 & 2,55 \\
\hline 261 & 1,29 & 1,43 & 1,55 & 1,73 & 1,84 & 1,98 & 2,29 \\
\hline 265 & 1,06 & 1,18 & 1,30 & 1,37 & 1,55 & 1,67 & 1,89 \\
\hline 269 & 0,95 & 1,05 & 1,13 & 1,23 & 1,36 & 1,46 & 1,67 \\
\hline 273 & $\underline{\mathbf{0 , 8 2}}$ & 0,90 & 0,97 & 1,08 & 1,18 & 1,26 & 1,45 \\
\hline 277 & $\underline{\mathbf{0 , 7 4}}$ & $\underline{\mathbf{0 , 7 7}}$ & $\underline{\mathbf{0 , 8 4}}$ & 0,94 & 1,04 & 1,14 & 1,29 \\
\hline 281 & 0,66 & $\underline{\mathbf{0 , 6 9}}$ & $\underline{\mathbf{0 , 7 3}}$ & $\underline{\mathbf{0 , 7 8}}$ & 0,88 & 1,01 & 1,18 \\
\hline 285 & 0,58 & 0,58 & 0,61 & 0,63 & $\underline{\mathbf{0 , 7 1}}$ & $\underline{\mathbf{0 , 8 6}}$ & 1,02 \\
\hline 289 & 0,51 & 0,52 & 0,52 & 0,53 & 0,56 & $\underline{\mathbf{0 , 7 0}}$ & $\underline{\mathbf{0 , 8 4}}$ \\
\hline 293 & 0,47 & 0,48 & 0,48 & 0,49 & 0,50 & 0,61 & $\underline{\mathbf{0 , 7 0}}$ \\
\hline 297 & 0,45 & 0,46 & 0,46 & 0,47 & 0,48 & 0,53 & 0,57 \\
\hline
\end{tabular}

The share of errors caused by deviations of $\mathrm{F}$ (force) and extract values $\mathrm{R}$ was very small. According to the user's manual, standard error in F assessment was smaller than $1 \%$ of measured values, and for simplicity in calculations this error was treated as constant value of $1 \mathrm{~N}$ (this was higher value than real). Standard error in extract assessment was 0,1 Brix.

\section{CONCLUSIONS}

Computer image analysis of starch-iodine patterns is a promising tool in S and SI values evaluations. Several conditions however should be fulfilled. Streif's Index expressed by several levels of starch index decomposition has different values changes among the whole maturation period.

The use of computer image analysis isn't a good solution when the starch content is high (for example Gloster cultivar), because of high level errors at initial stages of starch decomposition. The main reason of diminished precision of complex index such as Streif's Index is wide range of threshold, resulted in inaccuracies of starch index (S) an then Streif's index (SI) estimation.

It should be born in mind that most apple cultivars represent two different models of starch deterioration. The choice of these two different apple cultivars, as an example of two important indicators evaluation, was not an accident. Because of its different starch decline during maturation, detailed analysis was needed. The image of apple fruits represents circular type of starch deterioration (Gloster) should be analyzed at slightly higher levels of filtration thresholds, than the basic one (t120). Earlier studies (Peirs 2002) confirmed the results obtained in this study. In contradistinction to apples represent 
circular-type model of starch decline, the radial type apples (Rubin) of starch decomposition should be analyzed at lower filtration levels.

Prediction of fruits harvest date is possible when several conditions are fulfilled. The most important is reliability and accuracy of data put into calculation procedure. This leads to properly estimated harvest indicators before its inception. The issue of utmost importance is to continue research and laboratory work due to developing new measurements methods, which can become useful aids for optimization of fruits production, maintaining the product quality and making it more attractive for the consumer.

\section{REFERENCES}

Amissah J.G.N., Hotchkiss J.H., Watkins C.B. (2006). Diphenylamine and pre-slicing storage effects on the responses of apple slices to elevated $\mathrm{CO}_{2}$ atmospheres. Postharvest Biology and Technology, 39(2): 178-184.

Billy L., Mehinagic E., Royer G., Renard C., Arvisenet G. (2008). Relationship between texture and pectin composition of two apple cultivars during storage. Postharvest Biology and Technology, 47(3): 315-324.

De Long J. M., Prange R. K, Harrison P. A. (1999). Using the Streif Index as a final harvest window for controlled-atmosphere storage of apples. Hort Science 34(7), 1251-1255.

Doerflinger F. C., Miller W. B.,. Nock J. F, Watkins C. B. (2015). Relationships between starch pattern indices and starch concentrations in four apple cultivars. Postharvest Biology and Technology 110, 8695 .

Fellman J. K., Rudell D. R., Mattinson D. S., Mattheis J. P. (2003). Relationship of harvest maturity to flavor regeneration after CA storage of 'Delicious' apples. Postharvest Biology and Technology, 27: 3951.

Jackman P., Sun D.-W.,(2013). Recent advances in image processing using image texture features for food quality assessment. Trends in Food Science \& Technology 29, 35-43.

Malinowska-Pańczyk E., Kołodziejska I. (2010) Możliwości zastosowania wysokiego ciśnienia w przemyśle owocowo-warzywnym. ŻYWNOŚĆ. Nauka. Technologia. Jakość, 2(69): 5-15.

McGlasson W. B., Rath A. C., Legendre L. (2005). Preharvest application of aminoethoxyvinylglycine (AVG) modifies harvest maturity and cool storage life of 'Arctic Snow' nectarines. Postharvest Biology and Technology, 36(1), 93-102.

Morales H., Sanchis V., Rovira A., Ramos A. J., Marín S. (2007). Patulin accumulation in apples during postharvest: Effect of controlled atmosphere storage and fungicide treatments. Food Control, 18(11): $1443-1448$

Peirs A., Scheerlinck N., Perez A. B., Jancsók P., Nicolai B. M. (2002). Uncertainty analysis and modelling the starch index during apple fruit maturation. Postharvest Biology and Technology, 26: 199207.

Rutkowski K. (2001). Błędy popełniane przy określaniu terminu zbioru i podczas przechowywania jabłek. Ogólnopolska Konferencja. Skierniewice. Wydawnictwo ISiK: 69-74.

Song J., Bangerth F. (1996). The effect of harvest date on aroma compound production from 'Golden Delicious' apple fruit and relationship to respiration and ethylene production. Postharvest Biology and Technology, 8(4): 259-269.

Streif J., (1996). Optimum harvest date for different apple cultivars in the 'Bodensee' area. In De Jager A., Johnson D., Hohn E., (Eds.) COST 94, 9-10 June 1994. The postharvest treatment of fruit and vegetables: Determination and prediction of optimum harvest date of apple and pears. Lofthus, Norway, pp. $15-20$. 